\title{
The Medieval Reception of Geoffrey of Monmouth
}

\author{
Georgia Henley and Joshua Byron Smith
}

Geoffrey of Monmouth's work was read, adapted, and translated throughout Europe. The articles in this section provide an overview of this far-reaching reception in as many cultural traditions as possible. We have requested that contributors focus on the reception of Geoffrey's work proper, as opposed to the general efflorescence of Arthurian literature - a distinction that is admittedly not always easy to make. These articles are meant as points of entry into larger bodies of scholarship and are intended to stimulate further research. To that end, we have favored concision instead of comprehensiveness. In organizing the following essays under cultural and linguistic rubrics, we have relied on our contributors' expertise and our own judgment; readers are asked not to place too much importance on the various categories. Italy as we know it, for example, did not exist as such in the Middle Ages, and here Italy and other distinctions like it should be understood merely as convenient shorthand for the modern researcher. Finally, in spite of our best efforts, we suspect that we have omitted some aspect or another of Geoffrey's influence. Geoffrey's work might have been known in Poland, for example, or in the Hebrew language. ${ }^{1}$ And while multiple correspondents informed us that there was no Arabic reception, more research might prove otherwise. Unfortunate omissions are perhaps expected in such a large project, but we hope that these may be balanced by the wealth of information brought together here, much of it put in dialogue for the first time.

1 M. Schlauch, "Geoffrey of Monmouth and Early Polish Historiography: A Supplement", Speculum 44 (1969), 258-63. 